\title{
ANÁLISE BIBLIOMÉTRICA SOBRE INCUBADORAS DE EMPREENDIMENTOS
}

\section{BIBLIOMETRIC ANALYSIS ON BUSINESS INCUBATORS}

\author{
João Paulo do Carmo; Teresa Cristina Janes Carneiro ${ }^{2}$ \\ ${ }^{1}$ Universidade Federal do Espírito Santo, UFES- Vitória - ES - Brasil \\ joao.carmo@ifes.edu.br \\ ${ }^{2}$ Universidade Federal do Espírito Santo, UFES- Vitória - ES - Brasil \\ teresa.carneiro@ufes.br
}

\begin{abstract}
Resumo
Incubadoras de empreendimentos constituem-se um importante meio para o desenvolvimento empreendedor em todo o mundo, podendo ser de caráter público, privado, econômico ou social. Seu principal objetivo é desenvolver projetos inovadores por meio de um sólido programa de suporte tecnológico visando o crescimento das empresas que estão incubadas. Este estudo tem como objetivo analisar características bibliométricas dos artigos relacionados a incubadoras de empreendimentos em periódicos de alto impacto da área de empreendedorismo e inovação tecnológica, com um recorte longitudinal de 2000 a 2015. Trata-se de uma pesquisa exploratória de abordagem quantitativa e qualitativa. $O$ método utilizado baseia-se na sistematização do processo de busca e seleção de artigos proposta pelo ProKnow-C, fazendo uso de técnicas de análise bibliométrica considerando o que o pesquisador julga importante para o tema de pesquisa. A aplicação do método permitiu obter um portfólio bibliográfico com 14 artigos relevantes e de prestígio científico. Com esta pesquisa, pode-se fornecer ao pesquisador conhecimento sobre os periódicos mais relevantes para o tema, além de artigos e autores de destaque úteis para se iniciar uma pesquisa no tema incubadora de empreendimentos.
\end{abstract}

Palavras-chave: bibliometria; proknow-C; incubadora de empreendimentos.

\section{Introdução}

Segundo Maricato e Noronha (2012), o interesse de pesquisadores e envolvidos em políticas públicas em relação à comunicação e produção científica e tecnológica tem crescido há algumas décadas.

Estudos voltados à análise da produção científica no âmbito acadêmico visa verificar, dentre diversas questões, a qualidade científica. Esta produção de trabalhos, quando disponibilizada aos pesquisadores, realimentam todo o processo comunicativo além de contribuir para a construção do conhecimento. 
Sabemos como é vasta a quantidade e a qualidade dos artigos científicos existente nas mais diversas bases de dados científica. Uma das principais dificuldades de um pesquisador em sua pesquisa é identificar os artigos de maior relevância para o tema de seu interesse.

Diante desse fato, torna-se necessário o uso de ferramentas que auxiliam nessa seleção de artigos. Assim, consegue-se descobrir quais artigos tem maior impacto e delimitar o estado da arte do tema de sua pesquisa. Pensando nisso, pesquisadores da Universidade Federal de Santa Catarina desenvolveram um método de análise bibliométrica denominado Knowledge Development Process Constructivist - ProKnow-C (Ensslin, et al., 2010).

A aplicação deste método objetiva fazer uma filtragem e seleção de artigos de maior relevância para o tema de pesquisa. Segundo Afonso et al. (2011), a escolha do ProKnow-C justifica-se, pois o método é simples e eficaz na construção do conhecimento almejado pelo pesquisador.

Um estudo bibliométrico foca na análise de toda a produção científica de um determinado assunto, as citações e os conteúdos elaborados (MORETI; CAMPANARIO, 2009). Torna possível identificar quais são os autores e centros de pesquisas mais produtivos, por exemplo.

Desta maneira, esse artigo tem como foco realizar uma análise bibliométrica de publicações relacionadas ao tema "incubadoras de empreendimentos" entre os anos 2000 a 2015. Tal período justifica-se pelo conceito de incubadoras ter evoluído desde a década de 1970 e o movimento de criação de incubadoras ter crescido exponencialmente nos últimos anos (RATINHO; HENRIQUES, 2010).

O estudo justifica-se por buscar evidenciar o estado da arte das pesquisas relacionadas à incubadora de empreendimentos, na área de inovação tecnológica e empreendedorismo. Assim, a pesquisa deve facilitar futuras investigações, alinhando novas pesquisas àquelas publicadas em periódicos de alto impacto acadêmico, além de contribuir para ampliar a base metodológica e teórica das pesquisas com o referido tema.

Por fim, o artigo apresenta-se em cinco seções: (1) introdução; (2) referencial teórico; (3) esboço metodológico; (4) apresentação, análise e discussão dos resultados; (5) considerações finais.

\section{Incubadoras de empreendimentos}

As incubadoras de empreendimentos, de acordo com Scillitoe e Chakrabarti (2009) são reconhecidas com uma das formas organizacionais mais recentes e populares. Este conceito vem crescendo a partir da década de 1970, onde surgem as primeiras empresas de pequeno porte que precisavam de espaço de apoio a baixo custo. Estas empresas tinham como objetivo a gestão e formação de empreendedores (RATINHO; HENRIQUES, 2010). 
Incubadoras são ambientes de inovação que fomentam a cultura e a formação de empresas inovadoras. Esses ambientes geram produtos e serviços tecnológicos com alto valor agregado (LAHORGUE, 2008).

Dentre os principais objetivos de uma incubadora, podemos destacar o de transformar os negócios das empresas incubadas tornando-os mais competitivos, melhorando sua tecnologia e agregando mais valor aos produtos e serviços ofertados pelas empresas incubadas. Dessa forma, os empreendimentos vão para o mercado mais sólidos, gerando resultados lucrativos (BOLLINGTOFT, 2012; VANDERSTRAETEN; MATTHYSSENS, 2012; BRUNEEL et al., 2012).

Segundo Dornelas (2002), as incubadoras de empresas são mecanismos de desenvolvimento social e regional e um importante fomentador de empreendedores e empresas. Têm o intuito de incentivar o empreendedorismo, inovação e estão focadas na criação de novos produtos e novas empresas (SCHWARTZ; HORNYCH, 2010).

As principais funções que as incubadoras disponibilizam para seus incubados são as parcerias com outras empresas, fortalecimento de redes de relacionamentos e diversos tipos de consultorias (RATINHO; HENRIQUES, 2010). Pelo intermédio de uma incubadora de empresas, consegue-se, a longo prazo desenvolver mercados mais consistentes e dinâmicos, além de grandes projetos de caráter inovador (ENGELMAN; CARNEIRO; FRACASSO, 2015).

Engelman et al. (2015), afirmam que as incubadoras tecnológicas criam ambientes favoráveis ao desenvolvimento de novas tecnologias e projetos inovadores. Oferecem aos empreendedores incubados espaço físico, recursos organizacionais, assistência técnica aos seus empreendimentos e ajuda na gestão e proteção das tecnologias desenvolvidas. Dentro das incubadoras os empreendedores podem desfrutar de toda a rede de relacionamento da incubadora, além de ter a oportunidade de compartilhar experiências com outras empresas incubadas.

Para Dornelas (2002) e Martinéz-Costa e Jiménez-Jiménez (2009), as empresas que tem relação com o universo de uma incubadora e passam pelo processo de incubação dificilmente voltam ao patamar em que se encontravam caso não tivessem passado por uma incubadora de empresas.

\section{Metodologia}

A pesquisa possui etapas qualitativa e quantitativa (RICHARDSON, 1999). A etapa qualitativa faz a análise e seleção de artigos que deverão permanecer no portfólio bibliográfico. A etapa quantitativa consiste na análise bibliométrica do conjunto de artigos selecionados, 
descrevendo o perfil das publicações sobre o tema de pesquisa por meio da quantificação das ocorrências.

Em relação à coleta de dados, este trabalho concentrou-se em dados secundários provenientes de artigos científicos disponibilizados em texto completo nas bases de dados indexadas ao Portal de Periódicos da Capes.

A metodologia ProKnow-C, proposta pelo Laboratório de Metodologias Multi Critério em Apoio à Decisão - LabMCDA da Universidade Federal de Santa Catarina - UFSC, foi utilizado para os procedimentos de seleção e análise dos resultados adotados.

O ProKnow-C propõe quatro etapas na análise dos dados: (a) seleção do portfólio bibliográfico dos artigos relacionados ao tema da pesquisa; (b) análise bibliométrica do portfólio; (c) análise sistêmica do portfólio e (d) identificação do tema e do(s) objetivo(s) da pesquisa. Este artigo se concentrou nas duas primeiras etapas desta metodologia: a seleção de um conjunto de artigos sobre o tema da pesquisa e a análise bibliométrica destes artigos. Sendo assim, as subseções a seguir descreverão detalhadamente as duas etapas.

\section{Apresentação, análise e discussão dos resultados}

Nesta seção, evidenciam-se a seleção dos artigos utilizando o método ProKnow-C e os principais resultados encontrados.

\subsection{Seleção do portfólio bibliográfico}

Essa seção está dividida em três partes, seleção do banco de artigos brutos, seleção das bases de dados da pesquisa e filtragem dos artigos brutos, mostrando o passo a passo da seleção do portfólio bibliográfico.

a) Seleção do banco de artigos brutos: a seleção dos artigos sobre incubadoras de empreendimentos foi em periódicos qualificados na língua inglesa disponíveis nas bases de dados do Portal de Periódicos da Capes.

Para definição das palavras-chave, foram utilizados os termos “incubator", "business incubator" e "innovation center". As buscas por artigos foram realizadas fazendo combinações destes três termos-chave tanto no título do artigo quanto no resumo.

b) Seleção das bases de dados da pesquisa: o critério para a seleção das bases de dados, seguiu as informações sobre as bases no Portal de Periódicos da Capes. Foram selecionadas as bases com mais afinidade com o assunto da pesquisa: Web of Science, Science Direct, Proquest, Wiley e Spinger. 
Foi feita uma busca em cada base de dados, utilizando os termos-chave definidos anteriormente. Um dos critérios adotados foi procurar somente por artigos científicos na língua inglesa publicados nos últimos 15 anos (2000 a 2015). Outro critério adotado foi fazer uma filtragem, selecionando as categorias relacionadas à incubadora de empresas ou áreas afins, como por exemplo áreas ligadas a gestão e negócios.

Para cada base de dados foram realizadas três pesquisas, resultantes das combinações entre os termos-chave. Todos os 387 artigos selecionados foram enviados para o gerenciador de referências bibliográficas EndNote para serem analisados. A tabela 1 estratifica a quantidade de artigos por base de dados.

c) Filtragem dos artigos brutos: Inicialmente foram transferidos 387 artigos para o gerenciador de referências. Após verificar a duplicidade, 14 artigos foram excluídos restando 363 artigos. Realizada esta etapa, o próximo passo foi fazer a leitura dos títulos dos artigos verificando aqueles que não estavam em sintonia com o tema de pesquisa. Ao final desta etapa, foram excluídos mais 228 artigos, restando 135 artigos.

Seguindo o método ProKnow-C, a próxima ação foi a leitura integral dos resumos para observar com mais assertividade os artigos com foco principal em incubadoras de empreendimentos. Feito isso, foram eliminados mais 78 artigos, restando 57 artigos. A tabela 1 apresenta a quantidade de artigos selecionados em cada etapa e base de dados.

Tabela 1 - Quantidade de artigos selecionados por etapa e base de dados

\begin{tabular}{lccc}
\hline \multicolumn{1}{c}{ Base de Dados } & Artigos Selecionados & $\begin{array}{c}\text { Selecionados após Leitura } \\
\text { dos Títulos dos Artigos }\end{array}$ & $\begin{array}{c}\text { Selecionados após Leitura } \\
\text { dos Resumos }\end{array}$ \\
\hline Web of Science & 141 & 80 & 40 \\
Science Direct & 20 & 2 & 1 \\
Proquest & 28 & 13 & 5 \\
WILEY & 83 & 22 & 3 \\
Spinger & 91 & 18 & 8 \\
\hline TOTAL & $\mathbf{3 6 3}$ & $\mathbf{1 3 5}$ & $\mathbf{5 7}$ \\
\hline Fonte: Resurat
\end{tabular}

Fonte: Resultado da pesquisa (2016)

A etapa seguinte de filtragem dos artigos levou em consideração o reconhecimento científico. É necessário, nesta fase, determinar o número de citações de cada um dos 57 artigos que estão sendo analisados. Para isso, utilizou-se o número de vezes que um artigo foi citado em outros documentos fornecido pelo site Google Acadêmico.

Para o cálculo de representatividade científica da amostra (percentual acumulado de citações que os artigos mais citados representam) foi decidido um ponto de corte de permanência de 
$80 \%$ do total acumulado de citações, resultando em 16 artigos (cerca de $28 \%$ dos artigos do portfólio). Sendo assim, foram selecionados os artigos com mais de 105 citações. A Figura 1 apresenta o cálculo da representatividade científica mostrando o número de citações e a frequência acumulada em cada artigo.

Figura 1 - Banco de artigos quanto ao reconhecimento científico

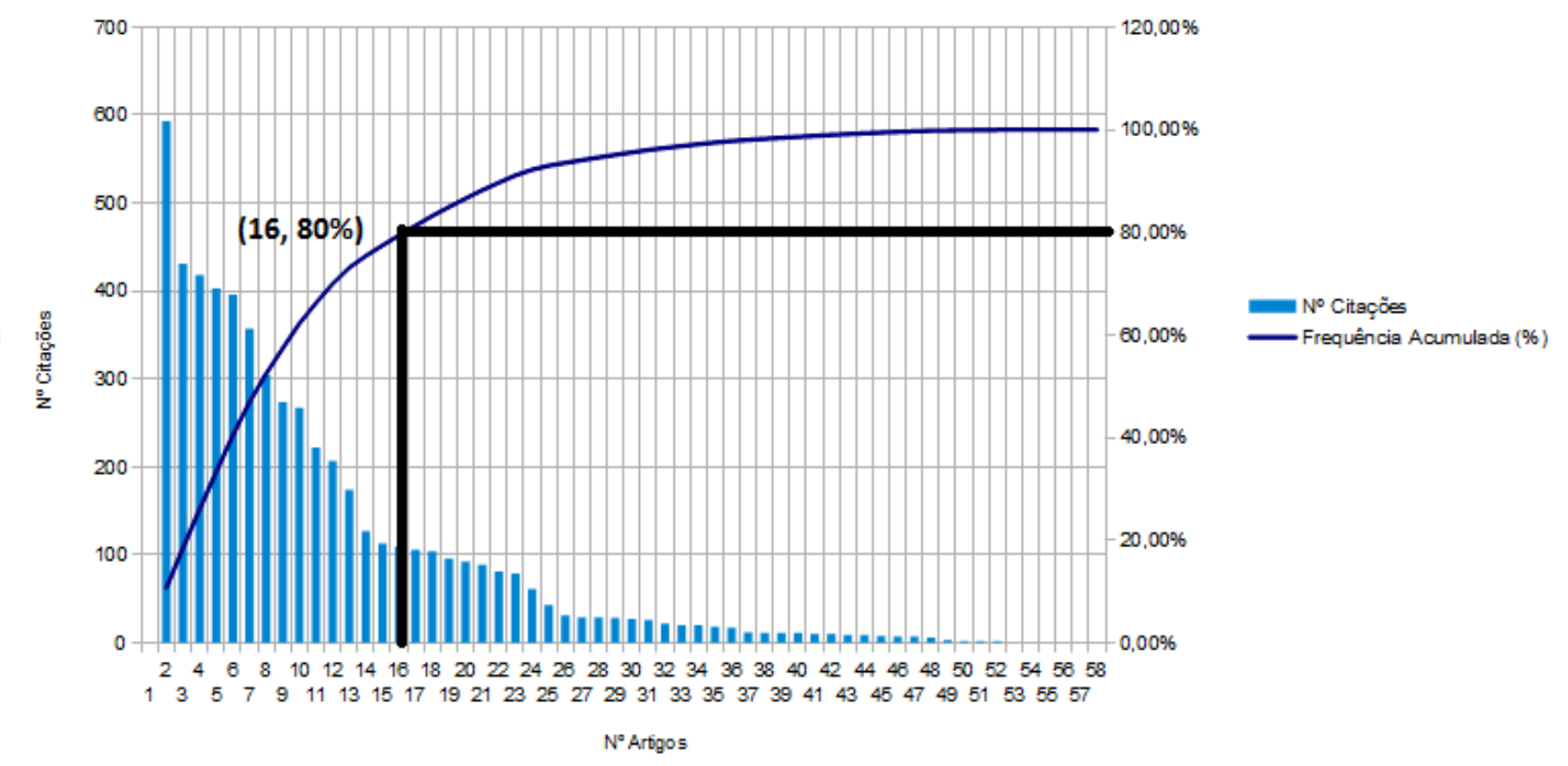

Fonte: Elaboração própria (2016)

De acordo com o método ProKnow-C, dos 41 artigos do portfólio descartados precisam ser selecionados os que possuem até dois anos de publicação. Portanto, foram resgatados 15 artigos publicados entre 2013 e 2015.

Dos 16 artigos selecionados com maior representatividade científica somados aos 15 artigos mais recentes, cinco não estavam disponíveis para download. Sendo assim, foram lidos 26 artigos na íntegra e 12 foram descartados por não serem totalmente alinhados com o tema de interesse da pesquisa.

Após a leitura dos artigos, chegou-se a um portfólio de 14 artigos alinhados ao tema “incubadoras de empreendimentos" apresentados na Tabela 2.

Tabela 2 - Portfólio Bibliográfico

\begin{tabular}{llccc}
\hline$\#$ & AUTORES & \multicolumn{1}{c}{ TÍTULO } & ANO & CITAÇÕES \\
\hline & Hackett, S. M.; & A Systematic Review of Business Incubation Research. & 2004 & 593 \\
1 & Dilts, D. M. & & & \\
& & & 2008 & 431
\end{tabular}


Norrman, C.

Grimaldi, R.; Business incubators and new venture creation: an assessment of

3 Grandi, A. incubating models.

4 Aernoudt, R.

Incubators: Tool for entrepreneurship?

2004

Peters, L.; Rice, The Role of Incubators in the Entrepreneurial Process.

5 M.

M.; Sundararajan,

2004

Aerts, K.;

Critical role and screening practices of European business

Matthyssens, P.; incubators.

Etzkowitz, H.; Towards "meta-innovation" in Brazil: The evolution of the

7 Mello, J. M. C.; incubator and the emergence of a triple helix.

Almeida, $\mathrm{M}$.

Scillitoe, J. L.;

The role of incubator interactions in assisting new ventures.

8 Chakrabarti, A. K.

Bruneel, J.;

The Evolution of Business Incubators: Comparing demand and

Ratinho, T.; supply of business incubation services across different incubator

9 Clarysse, B.; generations.

Groen, A.

Soetanto, D. P.; $\quad$ Business incubators and the networks of technology-based firms.

10 Jack, S. L.

Somsuk, N.; $\quad$ A fuzzy AHP to prioritize enabling factors for strategic

11 T.

Laosirihongthong, management of university business incubators: Resource-based view.

2014

Tavoletti, E.

Business Incubators: Effective Infrastructures or Waste of Public Money? Looking for a Theoretical Framework, Guidelines and Criteria.

Barbero, J. L.; $\quad$ Do different types of incubators produce different types of

Casillas, J. C.; innovations?

13 Wright, M.; Garcia,

R. A.

Anholon, R.; Silva, Features of management system developed by a reference business 14 M. C. incubator: the case of Celta Florianópolis.

Fonte: Elaboração própria (2016)

\subsection{Análise bibliométrica do portfólio}

As análises dos artigos do portfólio bibliográfico visam conhecer os artigos mais relevantes, os mais citados e os autores de destaque. As análises ocorreram em quatro etapas: a) estimativa das palavras-chave mais utilizadas, b) estimativa do grau de relevância dos periódicos, c) estimativa do 
reconhecimento científico dos artigos, d) estimativa do grau de relevância dos autores, resultando no conhecimento construído sobre o tema por meio do portfólio bibliográfico.

O método ProKnow-C permite que cada etapa avaliativa seja concluída, considerando as informações disponíveis nos artigos do PB. Além disso, a análise se estende-se para as referências dos artigos deste $\mathrm{PB}$, podendo haver cruzamento entre os dados.

a) Estimativa das palavras-chave mais utilizadas: foram identificadas 67 palavras-chave diferentes nos 14 artigos do PB. Porém, cabe ressaltar que três dos 14 artigos do PB apresentaram palavras-chave. Por isso, foi utilizada a lei de Zipf que identifica no texto as palavras mais frequentemente utilizadas. Os artigos foram convertidos para o formato txt e para a contagem e ranking das palavras mais frequentes foi utilizado o software Primitive Word Counter.

O software Iramuteq observou que, das 67 palavras-chave identificadas nos artigos do portfólio, 40 foram citadas apenas uma vez. A Figura 2 apresenta a frequência das palavras-chave nos artigos do portfolio. Pode-se observar que duas palavras-chaves mais se destacaram: "Business Incubator" e "Incubator". Essas palavras descrevem o tema da pesquisa e foram utilizadas como critério de seleção dos artigos.

Figura 2 -

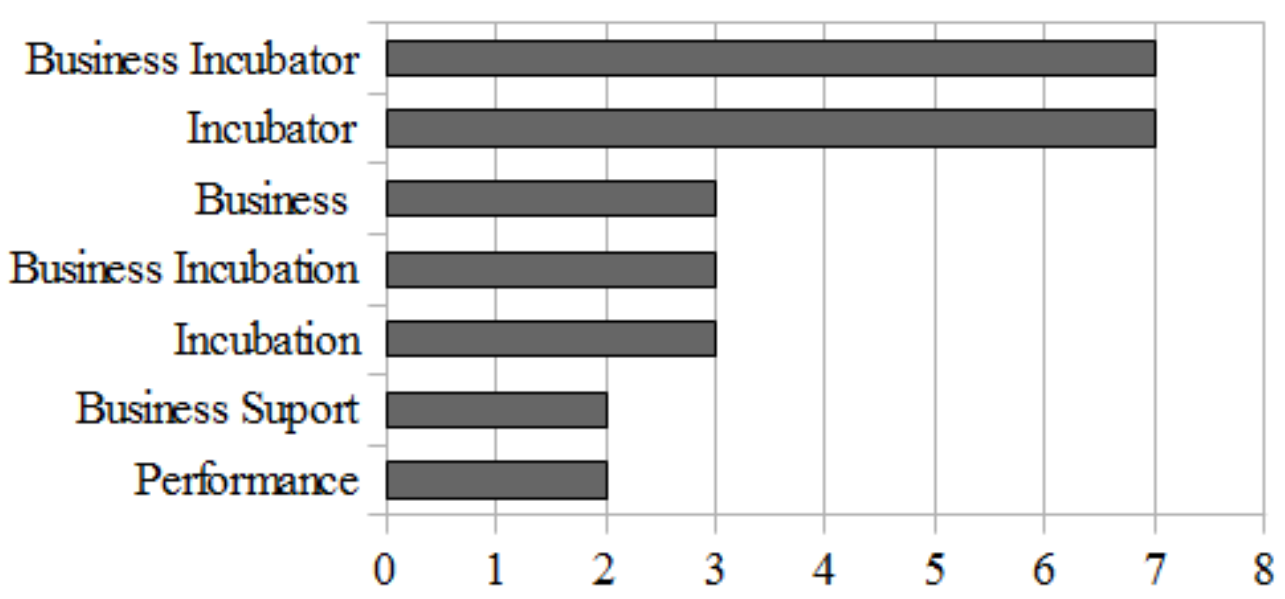

Palavraschave de destaque

Fonte:

Elaboração própria

\section{Estimativ}

a do grau de relevância dos periódicos: da análise dos artigos do portfólio, destacaram-se dois periódicos, Technovation e Journal of Technology Transfer, cujos assuntos de interesse são relacionados à inovação tecnológica e a transferência de tecnologia, temas alinhados às incubadoras de empreendimentos cujo foco é desenvolver novas tecnologias, gerir projetos inovadores e transferir conhecimento para o mercado (ELGELMAN et al., 2015). A Tabela 3 apresenta os periódicos em que foram publicados os artigos do portfólio bibliográfico. 


\section{JOURNALS}

\section{QUANTIDADE}

Technovation 5

Journal of Tecnology Transfer 4

Technological Forecasting \& social change

Small Business Economics 1

Research Policy 1

Journal of the Knowledge Economy

GEINTEC

Fonte: Elaboração própria (2016)

Outra questão que deve ser verificada na análise bibliométrica é o nível de relevância dos periódicos em que os artigos foram publicados.

O Qualis é o conjunto de procedimentos utilizados pela Capes para estratificação da qualidade da produção intelectual. Afere a qualidade dos artigos e de outros tipos de produção, a partir da análise da qualidade dos periódicos científicos. O Qualis está dividido em oito estratos, em ordem decrescente de valor: A1, A2, B1, B2, B3, B4, B5 e C.

O fator de impacto significa o número de citações que um periódico tem em um período de dois anos dividido pelo número de artigos publicados.

Outro coeficiente que mede a relevância de um periódico é o índice H. Publicado em 2005 por Hirsch, relaciona o número de publicações com o número de citações e cria um número que tem tendência a subir se a qualidade das publicações subir.

A Tabela 4 mostra o fator de impacto e o índice $\mathrm{H}$ para cada periódico do portfólio bibliográfico.

Tabela 4 - Fator de impacto e índice H

\begin{tabular}{lccc}
\hline \multicolumn{1}{c}{ JOURNALS } & QUANTIDADE & FI & ÍNDICE H \\
\hline Technovation & 5 & 2,53 & 72 \\
Journal of Tecnology Transfer & 4 & 1,18 & 45 \\
Technological Forecasting \& & 1 & 2,06 & 59 \\
social change & 1 & 1,79 & 73 \\
Small Business Economics & 1 & 2,32 & 142 \\
Research Policy & 1 & 0,74 & 6 \\
Journal of the Knowledge & & &
\end{tabular}


Fonte: Elaboração própria (2016)

Pela tabela pode-se observar que a maioria dos artigos está publicada em periódicos com alto valor de impacto, destacando-se as revistas Technovation e Research Policy. A revista GEINTEC, por se tratar de uma revista brasileira, não possui classificação internacional nem fator de impacto nem índice H. Pelo Qualis da área de Administração, Ciências Contábeis e Turismo do ano de 2014, é classificada como B3.

c) Estimativa do reconhecimento científico de artigos: A estimativa foi feita consultando o número de vezes em que o artigo foi citado no site Google Acadêmico (GOOGLE, 2014). A Tabela 5 apresentada para cada artigos do portfólio bibliográfico, o número de citações e a quantidade de referências encontradas em cada artigo.

Tabela 5 - Quantidade de citações e referências por artigo do portfólio bibliográfico

A Systematic Review of Business Incubation Research.

Business incubators and new venture creation: an assessment of

3 incubating models.

Incubators: Tool for entrepreneurship?

The Role of Incubators in the Entrepreneurial Process.

Critical role and screening practices of European business

6 incubators.

Towards "meta-innovation" in Brazil: The evolution of the

8 The role of incubator interactions in assisti ng new ventures.

9 The Evolution of Business Incubators: Comparing demand and supply of business incubation services across different incubator 
generations.

Business incubators and the networks of technology-based

10 firms.

A fuzzy AHP to prioritize enabling factors for strategic management of university business incubators: Resource-based view.

Business Incubators: Effective Infrastructures or Waste of

12 Public Money? Looking for a Theoretical Framework, Guidelines and Criteria.

Do different types of incubators produce different types of 13 innovations?

Features of management system developed by a reference

Fonte: Elaboração própria (2016)

Nos artigos do portfolio bibliográfico foram referenciados 809 artigos, em média 58 referências por artigo do portfólio. Considerou-se como destaque o artigo de Hackett e Dilts (2004) intitulado A systematic review of business incubation research, publicado no Journal of Technology Transfer, com 593 citações na data da consulta (Out/2015).

d) Estimativa do grau de relevância dos autores: não houve destaque entre os autores dos artigos do portfolio quanto à quantidade de artigos de sua autoria no portfólio. Todos os autores possuem apenas um artigo de sua autoria no portfolio. Logo, pode-se observar que o tema incubadora de empreendimentos é de interesse de autores diversos.

Entre autor e coautor, os 14 artigos do portfolio tiveram a participação de 33 autores, em média 2,36 autores por artigo. A Tabela 6 agrupa os artigos do portfolio por base de dados e número de autores.

\begin{tabular}{llllll}
\hline Base de Dados 1 Autor & 2 Autores & 3 Autores & 4 Autores & $\begin{array}{c}\text { Soma de } \\
\text { Artigos }\end{array}$ & $\begin{array}{c}\text { Soma de } \\
\text { Autores }\end{array}$
\end{tabular}




\begin{tabular}{lllllll}
\hline Web of Science & 1 & 4 & 2 & 2 & 9 & 23 \\
Science Direct & - & 1 & - & - & 1 & 2 \\
WILEY & 1 & - & - & - & 1 & 1 \\
Spinger & - & 2 & 1 & - & 3 & 7 \\
\hline TOTAL & 2 & 14 & 9 & 8 & 14 & 33 \\
\hline
\end{tabular}

Fonte: Elaboração própria (2016)

A base de dados Proquest não possui artigo selecionado no PB. Percebe-se uma concentração de autores na base Web of Science, que apresentou 23 autores em nove artigos.

A Figura 3 evidencia os autores que mais contribuem com artigos relevantes no portfólio bibliográfico e nas referências destes artigos. São 33 autores de 14 artigos do PB. Como no Portfólio Bibliográfico todos os autores tiveram apenas um artigo selecionado, o autor de destaque nas referências é o Sean M. Hackett com 14 referências, nenhuma autocitação. Outro autor de destaque é Rosa Grimaldi com 13 referências, porém com duas autocitações. Lois Peters também é destaque, porém das 11 citações, cinco são autocitações. Dos 33 autores do portfólio, nove citaram outros trabalhos de sua autoria nas referências dos seus artigos.

Figura 3 - Autores com maior participação no portfólio bibliográfico e suas referências

Fonte:

Elabora

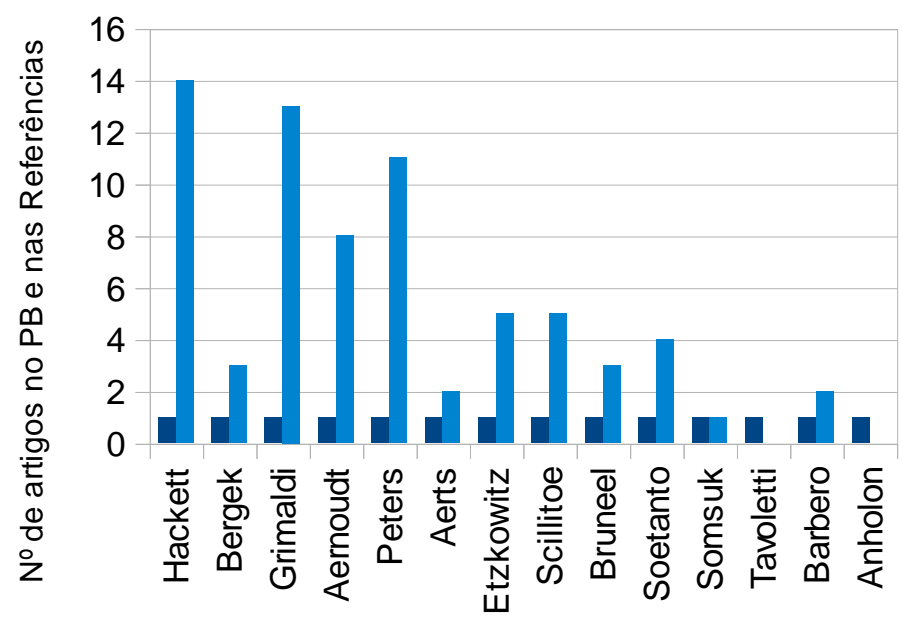
ção própria (2016)

Autores do PB

Artigos do PB

- Artigos das Referências

$$
\text { Em }
$$
relaçã o ao reconh ecime nto

científico dos artigos, foram identificados os artigos que mais se destacaram assim como seus autores; os artigos que foram escritos por autores que se destacaram dentro do PB; os artigos de destaque e os demais considerados importantes para a pesquisa.

A figura 4 e a Tabela 7 apresentam a análise da relevância dos artigos do portfólio bibliográfico e de suas respectivas referências. Essa análise considera o número de citações dos 
artigos de acordo com o Google Acadêmico comparado com a quantidade de vezes que o artigo foi citado nas referências do portfólio bibliográfico.

Figura 4 - Relevância dos artigos presentes no portfólio bibliográfico e suas referências

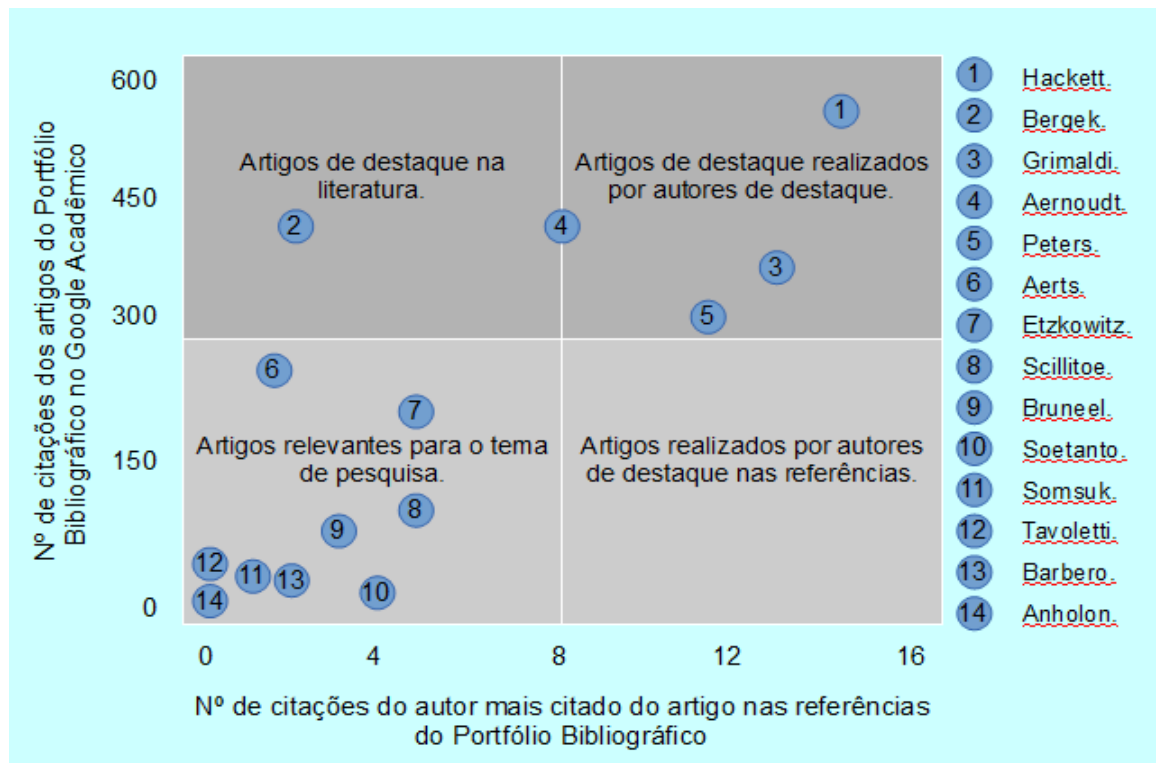

Fonte: Elaboração própria (2016)

Na Figura 4 há quatro quadrantes de classificação dos artigos do portfólio. Nenhum artigo foi enquadrado no grupo de artigos realizados por autores de destaque nas referências. Por outro lado, os artigos 1, 3, 4 e 5 (ver descrição dos artigos e autores na Tabela 7) estão entre os que mais se destacaram por sua relevância acadêmica.

O artigo 2 sobressai-se por ter sido produzido por autores de destaque na literatura. Os demais são classificados como artigos relevantes para o tema de pesquisa em questão.

Tabela 7 - Descrição dos artigos de maior destaque para o tema de pesquisa

\begin{tabular}{llll}
\hline$\#$ & \multicolumn{1}{c}{ Autores } & \multicolumn{1}{c}{ Título } & Ano \\
\hline & $\begin{array}{l}\text { Hackett, S. M.; Dilts, D. } \\
\text { M. }\end{array}$ & A Systematic Review of Business Incubation Research. & 2004 \\
& $\begin{array}{l}\text { Grimaldi, R.; Grandi, A. } \\
3\end{array}$ & $\begin{array}{l}\text { Business incubators and new venture creation: an assessment of incubating } \\
\text { models. }\end{array}$ & 2005 \\
& Aernoudt, R. & Incubators: Tool for entrepreneurship? & 2004 \\
& $\begin{array}{l}\text { Peters, L.; Rice, M.; } \\
\text { Sundararajan, M. }\end{array}$ & The Role of Incubators in the Entrepreneurial Process. & 2004 \\
\hline Fonte: Elaboração própria (2016)
\end{tabular}

Fonte: Elaboração própria (2016) 
A Tabela 7 descreve os artigos de maior destaque para o tema de pesquisa. Estes artigos foram escritos por autores de destaque e por serem os artigos mais citados, bem como pelas citações obtidas dentro das referências do Portfólio Bibliográfico.

O artigo intitulado de "A Systematic Review of Business Incubation Research", de Hackett e Dilts (2004), faz uma análise bibliográfica de artigos sobre incubadoras e incubação de empresas entre os anos 1984 a 2002.

$\mathrm{O}$ artigo "Business incubators and new venture creation: an assessment of incubating models”, de Grimaldi e Grandi (2005), buscou identificar variáveis existentes em incubadoras para poder evidenciar as principais diferenças entre os quatro tipos de incubadoras que os autores propõe e descrever os modelos de incubação.

Já o artigo “Incubators: Tool for entrepreneurship?”, da autora Aernoudt (2004), concluiu em seus estudos que um dos maiores obstáculos para o desenvolvimento de incubadoras de empresas na Europa é a falta de empreendedorismo e o subdesenvolvimento de financiamento em redes de negócio.

Por fim, o artigo de Peters, Rice e Sundararajan (2004), intitulado de "The Role of Incubators in the Entrepreneurial Process", buscou desenvolver um modelo para explicar como incubadoras de empreendimentos podem afetar o processo empreendedor.

\section{Conclusões}

É notório o crescimento da produção científica na última década e a tendência é que cresça cada vez mais. O pesquisador, ao passo que possui uma riqueza de informações disponíveis, precisa optar e selecionar os conteúdos de sua pesquisa. Logo, há uma dificuldade em estabelecer critérios para nortear o processo de seleção de conteúdo na busca de informações relevantes, como pode ser avaliado nesta pesquisa.

Diante do que se observa, há uma necessidade de metodologias eficazes na seleção de um portfólio bibliográfico para uma pesquisa científica. Este artigo teve como objetivo construir para o pesquisador, uma base para que pudesse pesquisar as lacunas do seu tema de interesse. Para isso foi utilizado o processo Knowledge Development Process - Constructivist (ProKnow-C), desenvolvido pelo LabMCDA da UFSC que sistematiza essa atividade de busca e selação, mesmo que com alguma subjetividade em relação a análise dos artigos e o entrosamento com o tema pesquisado.

O processo teve duas etapas: Seleção do Portfólio Bibliográfico e Análise Bibliométrica do Portfólio. Por delimitação do pesquisador, o estudo buscou artigos em bases de dados disponíveis no Portal de Periódicos da Capes, no período de 2000 a 2015. A seleção do Portfólio Bibliográfico 
sobre o tema "Incubadora de Empreendimentos" resultou na identificação de 14 artigos considerados os mais relevantes.

Os periódicos de destaque de acordo com a quantidade de artigos dentro do Portfólio Bibliográfico e nas referências foram Journal of Technology Transfer e Technovation. Os artigos de destaque, reconhecidos pela quantidade de citações de acordo com o site Google Acadêmico e com a quantidade de citações nos artigos do portfolio foram: A systematic review of business incubation research, de Sean M. Hackett e David M. Dilts; Business incubators and new venture creation: an assessment of incubating models, de Rosa Grimaldi e Alessandro Grandi; o artigo Incubators: tool for entrepreneurship? de Rudy Aernoudt e o artigo The role of incubators in the entrepreneurial process, de Lois Peters, Mark Rice e Malavika Sundararajan.

É válido mencionar que os resultados dessa pesquisa bibliométrica podem ajudar os pesquisadores interessados no tema a identificar autores e periódicos de destaque, sendo esses últimos mais suscetíveis a aceitar a publicações de pesquisas sobre o tema.

Como limitações da pesquisa destacam-se a busca bibliográfica dos artigos publicados em periódicos disponíveis apenas no Portal de Periódicos da CAPES; a consideração somente de artigos publicados em periódicos internacionais na língua inglesa, já que publicações em outros idiomas também podem ser de grande relevância para o tema; e a não utilização de outros instrumentos pesquisa, tais como: livros, dissertações e teses.

Para futuras pesquisas relacionadas ao tema incubadoras de empreendimentos, sugere-se aplicar a segunda fase da metodologia ProKnow-C, análise sistêmica do conteúdo do portfólio bibliográfico.

\begin{abstract}
Business incubators constitute an important means for the entrepreneur development throughout the world and can be public, private, economic or social character. Its main objective is to develop innovative projects through a solid technological support program to the growth of companies that are incubated. This study aims to analyze bibliometric characteristics of articles related to incubators in high impact journals in the area of entrepreneurship and technological innovation, with a longitudinal cut from 2000 to 2015. This is an exploratory study of quantitative and qualitative approach. The method used is based on the systematization of the search process and selection of articles proposed by ProKnow-C, making use of bibliometric analysis techniques considering what the researcher considers it important for the research topic. The application of the method yielded a bibliographic portfolio with 14 relevant articles and scientific prestige. With this research, we can provide the researcher knowledge of the most relevant journals for the subject, as well as useful articles and prominent authors to start a search on the topic business incubator.
\end{abstract}

Key-words: bibliometrics; proknow-C; business incubator. 


\section{Referências}

AERNOUDT. R. Incubators: Tool for Entrepreneurship? Small Business Economics, v. 23, n. 2, p. 127-135, 2004. crossref

AERTS, K.; MATTHYSSENS, P.; VANDENBEMPT, K. Critical role and screening practices of European business incubators. Technovation, v. 27, n. 5, p. 254-267, 2007. crossref

AFONSO, M. H. F.; SOUZA, J. V.; ENSSLIN, S. R.; ENSSLIN, L. Como construir conhecimento sobre o tema de pesquisa? Aplicação do processo Proknow-C na busca de literatura sobre avaliação do desenvolvimento sustentável. Revista de Gestão Social e Ambiental, v. 5, n. 2, p. 47-62, 2011.

ANHOLON, R.; SILVA, M. C. Features of management system developed by a references business incubator: the case of Celta Florianópolis. Revista GEINTEC, v. 5, n. 1, p. 1864-1880, 2015. crossref

BARBERO, J. L.; CASILLAS, J. C.; WRIGHT, M.; GARCIA, A. R. Do different types of incubators produce different types of innovations? The Journal of Technology Transfer, v. 39, n. 2, p. 151-168, 2014. cross ref

BERGEK, A.; NORRMAN, C. Incubator best practice: A framework. Technovation, v. 28, n. 1, p. $20-28,2008$. crossref

BOLLINGTOFT, A. The bottom-up business incubator: Leverage to networking and cooperation pratices in a selfgenerated, entrepreneurial-enabled environment. Technovation, v. 32, n. 5, p. 304-315, 2012. cross ref

BRUNEEL, J.; RATINHO, T.; CLARYSSE, B.; GROEN, A. The evolution of business incubator: comparing demand and supply of business incubation services across different incubator generations. Technovation, v. 32, n. 2, p. 110-121, 2012. cross ref

DORNELAS, José Carlos Assis. Planejando incubadoras de empresas: como desenvolver um plano de negócios para incubadoras. 2. ed. Rio de janeiro: Campus, 2002.

ENGELMAN, R.; CARNEIRO ZEN, A.; FRACASSO, E. M. The Impact of the Incubator on the Internationalization of Firms. Journal of Technology Management \& Innovation, v. 10, n. 1, p. 29-39, 2015. crossref

ENSSLIN, L. (et al.). ProKnow-C: Processo de análise sistêmica. Brasil: Processo técnico com patente de registro pendente junto ao INPI, 2010.

ENSSLIN, L.; ENSSLIN, S. R.; LACERDA, R. T. O.; TASCA, J. E. Processo de análise sistêmica. Processo técnico com patente de registro pendente junto ao INPI, 2010.

ETZKOWITZ, H.; MELlO, J. M. C.; ALMEIDA, M. Towards “meta-innovation" in Brazil: The evolution of the incubator and the emergence of a triple helix. Research Policy, v. 34, n. 4, p. 411-424, 2005. crossref

GRIMALDI, R.; GRANDI, A. Business incubators and new venture creation: an assessment of incubating models. Technovation, v. 25, n. 2, p. 111-121, 2005. crossref

HACKETT, S. M.; DILTS, D. M. A Systematic Review of Business Incubation Research. Journal of Technology Transfer, v. 29, n. 1, p. 55-82, 2004. crossref

LAHORGUE, M. A. Incubadoras de empresas no Brasil, quadro a partir das avaliações realizadas no período de 20002007. In: Jornadas Latino-Americanas de Estudos Sociais, das Ciências e das Tecnologias, Rio de Janeiro, 2008. Anais... Disponível em: <http://hotsites.sct.embrapa.br/proeta/informacoes/artigos-sobre-incubacao-deempresas/LAHORGUE20INCUBACaO20DE20EMPRESAS.pdf >. Acesso em: 17 nov. 2015.

MARICATO, J. M. ; NORONHA, D. P. Indicadores bibliométricos e cientométricos em CT\&I: apontamentos históricos, metodológicos e tendências de aplicação. In: HAYASHI, M. C. P. I.; LETA, J. (Org.). Bibliometria e Cientometria: reflexões teóricas e interfaces. São Carlos: Pedro \& João, 2012, v. 1, p. 21-41. 
MARTÍNEZ-COSTA, M.; JIMÉNEZ-JIMÉNEZ, D. The efectiveness of TQM: The key role of organization learning in small businesses. International Small Business Journal, v. 27, n. 1, p. 98-125, 2009. crossref

MORETTI, S. L. A.; CAMPANARIO, M. A. A produção intelectual brasileira em Responsabilidade Social Empresarial

- RSE sob a ótica da bibliometria. RAC, v.13, p. 68-86, 2009. crossref

PETERS, L.; RICE, M.; SUNDARARAJAN, M. The Role of Incubators in the Entrepreneurial Process. Journal of Technology Transfer, v. 29, n. 83-91, 2004.

RATINHO, T.; HENRIQUES, E. The role of science parks and business incubators in converging countries: Evidence from Portugal. Technovation, v. 30, n. 4, p. 278-290, 2010. crossref

RICHARDSON, R. J. Pesquisa Social: Métodos e Técnicas. São Paulo: Atlas, 1999.

SCHWARTZ, M.; HORNYCH, C. Cooperation patterns of incubator firms and the impact of incubator specialization: Empirical evidence from Germany. Technovation, v. 30, p. 485-495, 2010. crossref

SCILLITOE, J. L.; CHAKRABARTI, A. K. The role of incubator interactions in assisting new ventures. Technovation, v. 30 , n. 3, p. 155-167, 2010. crossref

SOETANTO, D. P.; JACK, S. L. Business incubators and the networks of technology-based firms. The Journal of Technology Transfer, v. 38, n. 4, p. 432-453, 2013. cross ref

SOMSUK, N.; LAOSIRIHONGTHONG, T. A fuzzy AHP to prioritize enabling factors for strategic management of university business incubators: Resource-based view. Technological Forecasting \& Social Change, v. 85, n. 1, p. 198210, 2014. crossref

TAVOLETTI, E. Business Incubators: Effective Infrastructures or Waste of Public Money? Looking for a Theoretical Framework, Guidelines and Criteria. Journal of the Knowledge Economy, V. 4, n. 4, p. 423-443, 2013. crossref

VANDERSTRAETEN, J.; MATTHYSSENS, P. Service-based differentiation strategies for business incubators: Exploring external and internal alignment. Technovation, v. 32, n. 12, p. 656-670, 2012. cross ref

\section{Dados dos autores:}

\section{Nome Completo: João Paulo do Carmo}

Filiação institucional: Universidade Federal do Espírito Santo

Função ou cargo ocupado: Estudante

Endereço completo para correspondência: Rua Carijós, 560, ap. 306, Jardim da Penha, Vitória - ES, 29060-700.

Telefones para contato: (27) 99527-0027.

E-mail: joao.carmo@ifes.edu.br

\section{Nome Completo: Teresa Cristina Janes Carneiro}

Filiação institucional: Programa de Pós-Graduação em Administração e Programa de Pós-

Graduação em Gestão Pública/UFES.

Função ou cargo ocupado: Professor.

Endereço completo para correspondência: Av. Fernando Ferrari, 514 - Goiabeiras, Vitória - ES, 29075-910.

Telefoness para contato: (27) 4009-2080.

E-mail: carneiro.teresa@gmail.com; teresa.carneiro@ufes.br

Submetido em: 23-06-2016

Aceito em: 21-09-2016 